\title{
The Impact of "Scramble for Talent" Campaign on College Graduates' Employment and Entrepreneurship in the Context of Indigenous Innovation and Industrial Upgrading
}

\author{
Yao Jingjun \\ Yancheng Teachers University (YCTU), Yancheng, Jiangsu, China
}

Received: March 15, 2020 Accepted: June 3, 2020 Published: June 24, 2020

doi: 10.5296/ire.v8i2.17240 URL: https://doi.org/10.5296/ire.v8i2.17240

\begin{abstract}
Indigenous innovation and industrial upgrading are the defining trends of economic development in the new era. With the formation of city clusters and the more scientific industry plant layout, the demand for talents in various cities is increasingly pressing. College students have become the major groups in the context of talent introduction policy. Major cities have initiated preferential policies to attract talents. The Scramble for Talent Campaign occurs among cities, making a considerable difference on the college graduates' employment and entrepreneurship. Since the initiation of "Scramble for Talent" campaign, the talent flow in relevant cities has accelerated measurably. The research shows that Hukou (the household registration) is the main element that the college graduates factor into consideration when selecting places of employment, and the fund and policy support they are able to receive are the key elements to promote innovation. In the "Scramble for Talent", such measures as relaxing restrictions on household registration policy, launching preferential loans policy and other support policies have considerably influenced on the college graduates' employment and entrepreneurship, which helps to optimize the distribution of talent resources and improve the willingness and success rate of entrepreneurship. In order to illustrate the effect, a series of policies and the transformation and upgrading of pillar industries are required in the introduction of talents. The blind scramble for talents will not only unbalance the allocation of human resources but will also cause social problems. It will spread the "City Disease" from the first-tier cities to the second and third-tier cities. The college students and all relative administration in all regions should pay high attention to this problem during the course. Generally speaking, the "Scramble for Talent" Campaign is a special phenomenon in
\end{abstract}


a special period, which positively impact the college graduates' employment and entrepreneurship.

Keywords: College Students' Employment, Industrial Upgrading, Talent Introduction, The Scramble for Talent Campaign

\section{Introduce}

The college students' employment has always been a subject of great concern to society. As a new force who have just made the entry into the society, college graduates enjoy a promising future. They are aggressive, vigorous and innovative, leading industries to generate vigor from within. Nowadays, China is carrying out industrial upgrading, which inevitably will eliminate outdated technologies. For that matter, only by seeking indigenous innovation can we promote industrial transformation and upgrading; only by enhancing the core competitiveness can we cultivate new economic growth points without reducing to a passive stance. Against this background, the demand for high-level talents in various industries is extraordinarily urgent.

Science and technology are the primary productivity force, which means that talents are the key powers behind it. Although there are many graduates every year with the expansion of enrollment in colleges and universities, high-level talents, as a cohort of special strategic resource, are in short supply at any time. Since 2016, major cities, especially the second-tier cities in the central and western regions of China, have launched such preferential policies in order to introduce talents as providing platforms for industrial upgrading, offering financial subsidies to improve people's well-being, and lift the restrictions on household registration policy, intensifying The "Scramble for Talent" Campaign. As result this movement will have an impact on the college students' employment and entrepreneurship and their future development, and this issue needs to be taken into account by new graduates.

\section{Background of Indigenous Innovation and Industrial Upgrading}

'Indigenous innovation' and 'industrial upgrading' are the new terms coined after the convening of the 18th National Congress of the Communist Party of China (CPC). According to the announcement made by the Third Plenary Session of the 18th Central Committee of the Communist Party of China, we should accelerate the transformation of economic development, build an innovative country, and make economic development more efficient, just and sustainable. The concept of industrial upgrading was put forward for the first time in the announcement above. In 2014, Premier Li Keqiang put forward the new concept of "mass entrepreneurship, mass innovation" at the summer Davos forum, setting off a resurgent and more forceful wave of "indigenous innovation" nationwide. The whole nation has witnessed the ability of indigenous innovation climbing and core competitiveness enhancing.

Since the initiation of reform and opening up four decades ago, China's industrial pattern has been modelled on that of foreign countries. In addition, there are other formulas that we have employed to obtain technologies overseas, such as offering huge market possibilities and establishing joint ventures, which have been essential to the overall improvement of China's industry sector. With the advantage of cheap labor resources and efficient government organization, China has rapidly achieved the huge increase in manufacturing volume, rending China a world factory and the second largest economy worldwide. Over this process, the 
accumulation of talents and capital is complete. However, it is undeniable that weaknesses abound in our manufacturing sector. For instance, the ability of our indigenous innovation is not robust enough to be in the driving seat in core technologies especially in the information technology (IT), material technology, artificial intelligence and other high technologies. Whereas in traditional industry such as steel, coal, cement sectors, we are saddled with much more serious overcapacity. Our traditional industry is facing the following new situation.

(1) The traditional industry is confronted with the great challenges with the advent of intelligent manufacturing led by information technology. Robots are the product of the integration of artificial intelligence and manufacturing technology, fueling the development of intelligent manufacturing industry. It is an irresistible trend that the robot will replace manual work in the future development of manufacturing industry, which will encourage the traditional manufacturing industry to be more intelligent.

(2) The industrial transfer of China's traditional industry is under way. Due to the shrinking dividend of Chinese demographic, the international manufacturing community is transferring its industries from China to Southeast Asia and India, thus posing huge challenges to the competitiveness of China's domestic traditional manufacturing industry. It in turn forces us to carry out industrial upgrading and structural adjustment promptly. At present, it is the status quo that the Eastern and Western cities are catching up in terms of economic development. Under the attraction of a series of talent and capital supporting policies in the central and western regions, the manufacturing industry in the eastern region is also relocating to the central and western regions. That may explain why the central and western regions have major strengths in undertaking the industrial transfer. However, talents is wanting badly in those regions.

(3) The competitiveness of China's core technology is insufficient. When China was in the downstream of the global industrial chain, it undertook the industrial transfer from developed countries. The gap in technology was pronounced, thus the technology transfer was relatively easy. In recent years, as the domestic labor cost has been up year by year and the cost advantage been down, the industries with low technology and low added value have to be transferred out. Moreover, the upstream industry chain is firmly monopolized by developed countries. Therefore, it requires us to improve competitiveness based on indigenous innovation, and to master core technology through innovation.

(4) "Internet plus" helps upgrade traditional industry. The "Internet plus", as a new concept, is a new development form that combines Internet with traditional industries. The traditional manufacturing and consumption patterns have experienced qualitative changes with the help of openness, convenience and high-speed information which define the Internet, generating a series of new business models. Nowadays, the "Internet plus" is the entrepreneurial platform in the new era of innovation.

\section{The Factors to Influence College Students' Employment and Entrepreneurship}

\section{1) employment places}

As the popularization of higher education in the new era and the expansion of university enrollment, the number of college graduates in China is increasing year by year. Also, over the recent years, with the rapid development of artificial intelligence, the room for job 
opportunity increases in various industries is shrinking, worsening the employment landscape for graduates. The employment of college students is a great concern to governments at all levels and the society. As high-quality talents, the choices of employment places and overall status quo of economic development of the place that graduates desire to locate is mutually affecting. According to the research and analysis of He Zhongyu[3], in terms of the factors to influence the choice of employment places, family and career upward mobility are the most important factors to be considered in employment. Promising development opportunities, social resources and good income are the main reasons why graduates prefer first-tier cities, but both the work and life pressure are what make them hesitate. With the housing prices skyrocketing in megalopolis, the living cost climbing, overpopulation and other "City Diseases" emerging, the happiness index of first-tier residents is declining. By contrast, thanks to the relaxed household registration and relatively lower life and work pressure, the second and third- tier cities are gradually favored by graduates. College students put first and second-tier cities into priority when they are seeking jobs. Family is an important factor that college students take into deliberation. The relatively loose household registration policy in the second and third- tier cities is an effective way to attract high-quality talents.

\section{Factors to Impact Entrepreneurship}

Global Entrepreneurship Monitor (GEM), jointly founded by London Business School and Baisen College, aim to study the dynamics and trend of entrepreneurial activities, analyze the relationship between the driving force of entrepreneurship and the economic growth, and evaluate the national entrepreneurial policy.

In the GEM model, as shown in Figure 1, the entrepreneurial environment is divided into nine sectors as seen in financial support, governmental policy, education and training, government projects, business environment and professional infrastructure, research and development transfer, openness of domestic market, availability of physical infrastructure, culture and social norms.

\section{Status Quo of College Students' Employment and Entrepreneurship}

According to the statistics of the Ministry of Human Resources and Social Security, the number of college graduates in 2018 reached up to 8.2 million. The overall growth of college graduates is driving down. Nevertheless, given that there still remain certain number of graduates who have not entered the job market, the employment pressure is still high. In recent years, in order to alleviate the demanding pressure on the employment of college students, governments at all levels have carried out reasonable scientific macro-regulations, and given considerable preferential policies to encourage college students' employment and entrepreneurship. College students' employment and entrepreneurship have taken on several features as follows:

(1) The employment pressure is considerable, and talents in emerging industries are in short supply.

(2) The second and third- tier cities have been preferred by more graduates in employment.

(3) The willingness to start a business is not strong enough. A survey by the Center for Entrepreneurship of Tsinghua University shows that the average level of entrepreneurship education in China is lower than that of GEM, which may be one of the reasons for the low 
willingness to start a business.

(4) The success rate of starting a business is at a low level. According to the 2015 report of Chinese college students' employment, more than half of the graduates who chose to start a business at first place directly quit the business three years later. In the eastern region with better economic status, the success rate of college students' entrepreneurship is barely $5 \%$.

\section{Analysis of the Influence of Scramble for Talent Campaign}

\section{1). Comparison of talent introduction policies in different regions}

The year 2017 witnessed a series of " Scramble for Talent" plans launched, such as "new policy of household registration" in Wuhan, "measures for the comfortable residence of talents" in Nanjing, "30 new measure for talents" in Jinan, "Chengdu RongPiao Plan" in Chengdu. In addition, Hangzhou, Xi'an, Shenyang, Changsha, Chongqing, Xiamen, etc. have all introduced preferential policies for the introduction of talents and joined the rank of "Scramble for Talent" movement, covering almost all second- tier cities. Among them, the undergraduate household registration policy and unconditional household registration policy have attracted many college students. For instance, 8000 graduates applied for household registration in Xi'an just in one day. This round of Scramble for Talents movement in various cities is a reflection of the development idea of local governments that gone are the days when the fast development was the only focus. To achieve this goal, a large number of talents need to be introduced. At present, this Scramble for Talent is just commencing, and the war will become more intensified in the future.

Many places attract talents by means of relaxed household registration, government subsidies and other approaches. In this regard, the author believes that simply lifting restrictions on household registration cannot retain talents. When formulating and implementing talent policies, each city should strike a balance among local natural endowments, economic structure and development goals, and provide industrial development prospects and effective incentive mechanism to retain talents. In 2017, new policies of talents' household registration was introduced intensively to attract talents. In the first quarter of 2018, the Scramble for Talent Campaign was upgraded, and more practical preferential measures were introduced. Besides the second- tier cities, the first- tier cities of Beijing, Shanghai, Guangzhou and Shenzhen also joined in the Scramble for Talent movement. The specific measures center on relaxing restrictions for household registration provide living subsidies for renting and buying houses, and providing entrepreneurial loans. In terms of the employment household registration conditions, the threshold is lowered and open to undergraduate. Some cities even lower the standard and made the policy accessible to associate degree graduates. In Xi'an, all college students in China can apply for household registration online only with student card and personal ID card.

\section{2). Achievements since the Scramble for Talent}

For a long time, the first- tier cities have attracted a large number of talents by taking the advantages of industrial clusters. However, with the rapid increase of the living cost in the first- tier cities, especially the cost of housing, the college students who have just stepped into the society are deterred, and the phenomenon of "escaping from Beijing Shanghai and Guangzhou" has appeared. Nowadays, driven by the industrial upgrading as found in 
second-tier cities, the industrial environment in these cities has improved significantly, and the huge gap in talent demand for a long time has finally ushered in a turnaround. Therefore, since the Scramble for Talent in 2017, the effect of talent policies in different regions has been obvious, and the Scramble for Talent has promoted the flow of talents.

According to the employment data released by Nanjing Municipal Bureau of Human Resources and Social security in the first quarter of this year, among the 105000 people registered for employment and insurance in Nanjing for the first time, there are 69,000 talents with college degree or above, accounting for $66 \%$. With a year-on-year increase of $27 \%$, more than $80 \%$ of them are college students from other places. That is to say, the number of newly registered and newly employed college students increased significantly in the first quarter at the same pace.

According to the data released by the Public Security Bureau of Xi'an city, 244,978 talents registered household in the first quarter. Among them, 392 are Ph.D holders or above, 6689 are masters, 74960 are undergraduates, and 50233 are junior college students. It's nearly 10 times more than the number of people (26130 people) who registered household in the first quarter of 2017. In particular, on March 23, 2018, on the day of the announcement of the new household registration policy of "household registration application only with student card and ID card" for college students in Xi'an, a total of 8050 people moved in and settled down, breaking the previous record.

According to the data released by Wuhan, 301,000 graduates stayed for entrepreneurship and employment and 142,000 new residents settled down in Wuhan, reaching a record high. In the first quarter of this year, nearly 100,000 graduates stayed in Wuhan for entrepreneurship and employment.

3). The impact of college students' employment and entrepreneurship

The competition for talents reflects the importance attached by all regions to talents. It helps to promote the flow of talents to the second and third- tier cities, invigorating once flourishing entrepreneurial places. Also it plays a good role in supporting the economic transformation and upgrading. According to the inflow data of urban household registration in last year and the first quarter, it is particularly true. As new graduates are the main target in the Scramble for Talent, household registration is the decisive factor in the choice of graduates' employment. Because of this, all cities will relax the requirement of household registration without exception, which will have a positive impact on the choice of graduates' employment and the possible entrepreneurship in the future. The "Scramble for Talent" is only a superficial phenomenon, and the corresponding preferential policies will have a profound impact on the college students' employment and entrepreneurship.

(1) It provides more opportunities for college students. As all major cities are open to the new college students, college students can make better choices according to their college majors and the needs of the industrial structure of the city, thus helping to promote the quality and quantity of college students' employment, reasonably allocating talents, and maximizing the benefits of social resources.

(2) It can promote the professional ability of college students. While attracting talents, the local authorities have also taken the difficulties they may encounter into consideration, 
including providing preferential policies such as house purchase subsidies, rental subsidies, living subsidies, minimum wage guarantee, so on and so forth. The preferential subsidies are of great help to graduates who are just starting their careers and who are in poor economic conditions. It is conducive to their secure employment and entrepreneurship. A stable job can improve their ability.

(3) It can further promote the entrepreneurship of college students. All cities have generally issued preferential policies to support entrepreneurship, such as setting up funds for college students to start their own businesses, opening up green channels, and providing comprehensive policy support for college graduates to start their own businesses. It enables more college students to join the tide of entrepreneurship and make their own dream in entrepreneurship a reality.

Both the central government and the local governments emphasize innovation and entrepreneurship, and encourage college students to start their own business by implementing the policies in loans, tax preferences, industrial support, etc. According to the influencing factors in GEM model, financial support and governmental policy need to put on high agenda. With the rapid development of China's market economy, other factors have basically met the conditions. Therefore, the preferential policies and financial support in the "Scramble for Talent" are not only the key constraints to the success of college students' entrepreneurship, but also the important factors to improve the enthusiasm of college students' entrepreneurship.

\section{Issues Needed to Be Taken Care of}

It can be seen that the Scramble for Talent has a significant effect on the introduction of talents and has a positive impact on the entrepreneurship and employment of college students. However, we need to pay attention to the following three aspects:

Firstly, we need to implement and improve policies and avail of and retain talents. The preferential policies for the introduction of talents should be sustainable, constantly adjusted, and keep pace with the times. Policies cannot just be used to attract talents which is just the first step, while making the most of talents and retaining talents are the ultimate goal. We should take comprehensively measures from the aspects of industrial structure, administrative efficiency, urban construction, education and health and other talent development needs. Moreover, we should pay attention to the implementation of policies so that the talents introduced can be made best of and play an effective role.

Secondly, we should be cautious with the Scramble for Talent. For cities, it is necessary to accurately introduce talents in combination with its own positioning and development stage, and should not follow the herd. It is rational for the cities that have made great progress in innovation, entrepreneurship, transformation and upgrading to join the Scramble for Talent, while the cities that do not have sufficient development in industrial structure need to be cautious to avoid waste of talents. For college students, we should not be attracted by temporary preferential conditions. The college students should consider the prospect of career development and the industrial support, so as to avoid blind selection.

Thirdly, we should be watchful about a new round of imbalance in talent flow.

At present, the rapid introduction of talents may cause the imbalance of regional talent 
structure and aggravate the imbalance of talent distribution. It is effective and should be approved to attract talents. However, for a long time, we have also emphasized and encouraged college students to work in rural and remote areas and other places with backward economic development. If the Scramble for Talent is not contained, it will produce negative effects, which is not conducive to the long-term healthy and orderly development of talent introduction. Therefore, it requires the government organs to carry out reasonable and optimized allocation from a higher level. We are glad to see that in the Scramble for Talent, many local governments keep rational while seeking for talents. Many local party committees have set up "talent office", which is usually subordinate to the Organization Department of the Party Committee. Under the strong and effective leadership of the Organization Department, they have formulated talent introduction plans and schemes suitable for the region, instead of going with the flow. The introduced talents can start businesses and be innovative and productive in an environment suitable for themselves, which injects new impetus into the upgrading of local industries.

The Scramble for Talent is a special phenomenon aimed at introducing talents into secondtier cities in the context of indigenous innovation and industrial upgrading. Generally speaking, it is beneficial to improve the urban and regional economic development and promote the employment and entrepreneurship of college students. In terms of industrial upgrading, innovation and entrepreneurship, the talent is the core, education is the foundation. Under the background of "The Scramble for Talent", the government should guide colleges and universities to take entrepreneurship education as a systematic strategic plan and take entrepreneurship education as an important task to further education system reform. Colleges and universities should incorporate entrepreneurship education into students' education plans while considering the students' future development plans so as to achieve the perfect integration of entrepreneurship education and education. Additionally, colleges and universities should assimilate relevant policies to support college students' innovation and entrepreneurship into teaching, and correctly guide the direction of entrepreneurship education in colleges and universities, so that college students can quickly obtain entrepreneurship information, get access to service media, and avoid repeating mistakes when they launch their own startups. I believe that after this round of Scramble for Talent, both the employment and entrepreneurship environment and the entrepreneurship education of college students will be improved.

\section{Acknowledgement}

Fund project: 2018 annual project: Research on the Cultivation of Innovative Talents in Local Universities from the Cultural Perspective supported by the Humanities and Social Sciences Research Planning Fund Project of the Ministry of Education of China (No.: 18YJA880109, Project Leader: Yao Jingjun).

Special Project of Ideological and Political Affairs of Philosophy and Social Science in Colleges and Universities of Jiangsu Province (Project Approval No.: 2018SJSZ494).

\section{References}

Guan, X., \& Zhao, Y. X. (2017). A Brief Analysis on the Current Situation of College Students' Entrepreneurship. Economic Research Guide, 2(1), 72-73. 


\section{Macrothink}

International Research in Education

ISSN 2327-5499 2020, Vol. 8, No. 2

He, Z. Y., \& Zhai, G. F. (2015). An Analysis of China's College Students' Willingness to Choose A City for Employment and Its Influencing Factors. Cultural Geography, 37(2), 37-40.

Meng, J. H., \& Xian, Y. M. (2017). Research on the Financing Channels of College Students' Entrepreneurship In the Context of Industrial Transformation and Upgrading. Knowledge Economy, 12(1), 167-167.

Wang, J. W. (2017). The Background and Significance of College Students' Innovation and Entrepreneurship. Cultural Education, 20(1), 308-309

Zhang, X. D., \& Wang, H. L. (2011). The Construction of the Strategic System of College Students' Entrepreneurship and Employment. Continuing Education Research, 10(3), 110-112.

\section{Copyright Disclaimer}

Copyright reserved by the authors.

This article is an open-access article distributed under the terms and conditions of the Creative Commons Attribution license (http://creativecommons.org/licenses/by/4.0/). 